\title{
PROFESSOR REFLEXIVO: DA TEORIA A UMA NOVA UNIVERSIDADE
}

\section{ARTIGO ORIGINAL}

FERNANDES, Devanir Ramos ${ }^{1}$

MACHADO, Alexsandro Dos Santos ${ }^{2}$

FERNANDES, Devanir Ramos. MACHADO, Alexsandro Dos Santos. Professor reflexivo: da teoria a uma nova universidade. Revista Científica Multidisciplinar Núcleo do Conhecimento. Ano 04, Ed. 09, Vol. 01, pp. 98-115. Setembro de 2019. ISSN: 2448-0959, Link de acesso: https://www.nucleodoconhecimento.com.br/educacao/nova-universidade

\section{RESUMO}

Ao introduzir o conceito de professor reflexivo, levanta-se algumas críticas à racionalidade técnica, destacando sua incapacidade para lidar com o imprevisível, uma vez que a mesma mecaniza o pensamento negando o mundo real da prática vivida, reduzindo o conhecimento prático do professor a um conhecimento como técnica. Analisando a amplitude da presença do conceito na literatura educacional sobre formação de professores, quer na formação inicial, quer na continuada, e mesmo as possíveis críticas que a abordagem suscita, além da aqui apresentada e buscando considerar as pertinências das diversas posições sobre a questão. Os professores são guiados em sua ação educativa por sua história pessoal e cultural, mas que também fazem opções sucessivas e que marcam sua trajetória, não estando inteiramente à mercê das circunstâncias socioculturais e das condições pessoais,

\footnotetext{
${ }^{1}$ Mestrando Em Educação, Pela UDE (Universidad De La Emprensa, Montevideo, Uruguai). Licenciatura Plena Em Filosofia Pela USC (Universidade Do Sagrado Coração, Bauru, SP. Teologia Pela Fajopa (Faculdade João Paulo II Marilia, SP.

${ }^{2}$ Doutorado em Educação; Mestrado em Educação; Graduação em Psicologia.
} 
interferindo nelas intencionalmente. Tendo uma consciência intencionada, por meio da qual compreendem a realidade e a possibilidade de nela intervirem, sendo sua consciência atribuidora de sentidos e por meio dela têm a possibilidade de se descobrirem e se posicionarem frente ao mundo, escolhendo como fazer, realizar suas vidas. Assim pode entender que mesmo com a predominância de uma formação voltada para a racionalidade técnica o professor faz uso de sua capacidade reflexiva e um horizonte animador se estabelece uma vez que vivemos uma tendência de colocar a reflexão em lugar central na formação docente, logo as condições de elevar o professor ao status de sujeito efetivo do conhecimento estão se estabelecendo.

Palavras-Chave: Professores, formação, professor reflexivo.

\section{INTRODUÇÃO}

Muito se fala em formação de professores de nível básico, fundamental e médio, porém não se tem dado muita importância à formação de professores para o ensino superior. Tal fato é verídico visto que muitos dos professores universitários não possuem a didática necessária para a construção do conhecimento e é comum escutarmos dos alunos que determinado professor sabe a matéria, porém não consegue transmiti-la, ou que conduz mal a aula. Cobra-se do professor universitário que ele tenha pleno domínio sobre a disciplina que leciona, seja este domínio prático ou epistemológico e deixa-se de lado o domínio pedagógico. Atualmente o professor já não é mais conhecido como o detentor do saber, do conhecimento e sim como um mediador que auxilia seus alunos e cria possibilidades para a produção do conhecimento, incentivando a criticidade e a reflexão, construindo juntos este conhecimento embasados em questionamentos e teorias constantemente renovadas. Para Zeichner(1992) essa renovação passa por três características primordiais. A primeira diz respeito a reflexão sobre a prática dentro do espaço da ação, sala de aula. A segunda é quanto aos objetivos democráticos e emancipatórios dos alunos. A terceira característica do professor reflexivo diz sobre o trabalho com o grupo todo e não com alguns apenas 
A partir da nova configuração educacional, as discussões relacionadas à formação de professores têm colocado em lugar de destaque a questão da reflexão, que é uma tendência em ampla divulgação. Donald Schön é um dos teóricos de destaque na discussão acerca do professor reflexivo, sendo ele, sem dúvida, um dos autores que teve maior peso na difusão do conceito de reflexão. Dessa forma, em situações acidentais, singulares, em que há conflitos de valores, ganha destaque o caráter da reflexividade na atuação do profissional. A ideia do profissional reflexivo busca considerar a forma como esse profissional enfrenta situações que não podem ser resolvidas com o uso de recursos técnicos. Nesse modelo, o conceito principal no processo de formação é o da profissionalização centrada no comprometimento com uma prática reflexiva e com a aquisição de saberes e competências retirados da análise da prática. (PAIVA, 2003)

Após conceber a crítica à racionalidade técnica, Schön (2000) afirma que o pensamento prático do professor envolve algumas dimensões que são interdependentes: o conhecimento na ação, a reflexão na ação e a reflexão sobre a ação. O conhecimento na ação refere-se aos conhecimentos que se manifestam no saber-fazer, são ações automáticas, espontâneas. O conhecimento não precede a ação, mas está tacitamente encarnado nela.

A reflexão na ação acontece quando pensamos sobre o que fazemos ou quando pensamos enquanto fazemos algo. Esse processo de reflexão na ação não é necessariamente pontual e rápido, podendo transformar o profissional em um investigador no contexto da prática. Assim sendo, a prática é vista como um modo de investigar, de experimentar a situação possibilitando uma nova compreensão. A reflexão sobre a ação possibilita a análise do conhecimento na ação e a reflexão na ação introduzidos no contexto da própria prática. A reflexão tende a focalizar de forma interativa nos resultados da ação, sobre a própria ação e sobre o conhecimento intuitivo implícito na ação, objetivando descrever, analisar e avaliar a intervenção passada. A reflexão sobre a ação e sobre a reflexão na ação são, segundo Schôn (1992), componentes essenciais no processo de formação continuada do profissional. 
O componente institucional da prática profissional não é ignorado por Schôn (1992), sendo que a reflexão docente pode colocar em questão os limites burocráticos na definição de suas tarefas e nos valores que a instituição assume. $O$ autor considera ainda que a prática reflexiva não pode acontecer alheia ao contexto social em que ocorre, uma vez que os profissionais nela envolvidos são vistos como participantes de uma ampla conversação social enquanto desempenham seus papéis.

\section{REFERENCIAL TEÓRICO}

A maioria dos professores universitários inicia-se na docência trilhando um caminho desconhecido, muitos dormem alunos e acordam professores, pois não existe uma formação específica para professor do ensino superior, com isso a ausência de uma formação didático-pedagógica tem sido um obstáculo para o bom desempenho do professor universitário e consequentemente um ensino superior de qualidade. Segundo Tardif (2000) em suma, as fontes da formação profissional dos professores não se limitam à formação inicial na universidade; trata-se no verdadeiro sentido do termo de uma formação contínua e continuada que abrange toda a carreira docente. Para ingressar no magistério superior, segundo a legislação educacional, ou seja, a Nova Lei de Diretrizes e Bases da Educação Nacional (Lei no. 9394/96), no Capítulo $\mathrm{VI}$, artigo 66 cita:

Art.66. A preparação para o exercício do magistério superior far-se-á em nível de pós-graduação prioritariamente em programas de mestrado e doutorado.

Parágrafo único. O notório saber, reconhecido por universidade com curso de doutorado em área afim, poderá suprir a exigência de título acadêmico.

Porém nem todo aquele que possui uma pós-graduação, mestrado ou doutorado está apto a ser professor do ensino superior, por mais que o profissional tenha um destes títulos se nesta formação não conste as disciplinas didático pedagógicas necessárias para o magistério superior o mesmo não se encontrará habilitado para lecionar em nível superior. 
O parágrafo único deste mesmo artigo abre as portas da docência superior para qualquer indivíduo, mesmo sem formação regular, visto que tenha saberes reconhecidos em determinada disciplina, por universidade com curso de doutorado em área correlata à disciplina em que se destaca.

A titulação em si só não garante a qualidade do ensino, pois muitas IES exigem que seus docentes atuem em áreas além de suas habilidades, para que com isso consigam cumprir outra exigência da LDB (9.394/96) que no art. 52 incisos II enfatiza a titulação do corpo docente.

Art. 52. As universidades são instituições pluridisciplinares de formação dos quadros profissionais de nível superior, de pesquisa, de extensão e de domínio e cultivo do saber humano, que se caracterizam por:

I - Produção intelectual institucionalizada mediante o estudo sistemático dos temas e problemas mais relevantes, tanto do ponto de vista científico e cultural, quanto regional e nacional;

II - Um terço do corpo docente, pelo menos, com titulação acadêmica de mestrado ou doutorado;

III - um terço do corpo docente em regime de tempo integral. Parágrafo único. É facultada a criação de universidades especializadas por campo saber.

Portanto, o docente universitário deve ter conhecimentos e habilidades para ser um profissional reflexivo e investigativo para que possa refletir sobre sua prática docente, ajudando seus alunos a construir seus saberes de modo que estes também se tornem profissionais críticos e reflexivos.

Segundo Paulo Freire (2003) a educação possui caráter político e é impossível ao educador permanecer imparcial a isso, com isso o professor deve ter comprometimento com alguma ideia e defendê-la respeitando todas as opiniões contrárias, sendo assim, o educador deve ser formado sem autoritarismo respeitando a democracia e ensinando a importância disso a seus alunos. 
Zeichner (1993) apud Paiva (2003), sem rejeitar os conhecimentos provindos e produzidos nas universidades e centros de investigação, destaca que os professores possuem teorias que podem contribuir para a melhoria do seu cotidiano escolar. $O$ autor ampara a origem do termo prática reflexiva em Dewey(2008), destacando que grande parte da produção desse ainda continua relevante aos professores, sendo que o mesmo afirma que a reflexão é uma forma, uma maneira de ser professor. O fato da concepção de reflexão apresentada por Schön (1992) dar a entender que os profissionais se envolvem individualmente em práticas reflexivas é criticado por Zeichner (1992), que considera esse enfoque limitado e reducionista para o sentido que uma prática reflexiva deveria ter.

Segundo Paiva (2003), Zeichner identifica e emprega princípios que se articulam com o conceito de professor como prático reflexivo. O primeiro princípio se refere ao fato de que na prática do ensino reflexivo a atenção do professor está voltada para sua própria prática como para as condições sociais nas quais essa prática está situada.

Outro princípio está ligado a um foco democrático e emancipatório, ou seja, situações de desigualdade e injustiça em sala de aula devem ser consideradas nas decisões do professor. Por fim, uma prática reflexiva é compromissada com a reflexão enquanto prática social. É possível detectar nas perspectivas de Zeichner acerca da reflexão na prática, uma orientação em busca da reconstrução social, a sobressalência de um esforço de contextualização do social e de problematização ideológica e política do ensino e da formação de professores.

Para Jesus (1999) a formação de professores pode se constituir enquanto um instrumento para a aquisição de competências profissionais relevantes que aumentem a autoconfiança e a probabilidade de sucesso do professor. Com relação à formação inicial de professores, Santos (2002) aponta para a necessidade de se repensar o currículo no sentido de ultrapassar a lacuna existente entre a teoria e a prática, isto é, a necessidade de se estabelecer a interligação entre ambas.

Para Esteve (1997) apud Jesus (2002) a formação inicial do professor deveria desenvolver a capacidade de o mesmo identificar seu estilo de ensino, de discriminar 
os problemas relacionais que podem ocorrer na sala de aula e também de perspectivar a resolução de problemas em decorrência das atividades de ensino-aprendizagem. Portanto, os professores, em sua formação inicial, precisam estar preparados para identificar e confrontar as dificuldades existentes na atividade docente, no sentido de serem colocados em situações de antecipação do seu futuro profissional, clarificando as expectativas sobre as possíveis situações com que irão se confrontar (JESUS, 2002).

A preocupação com formação continuada de professores universitários vem crescendo nos últimos anos, fato este tem se notado devido ao crescimento de congressos, cursos e seminários relativos ao tema, esta preocupação tem-se dado pela expansão do ensino superior e o crescente número de docentes, que na maioria das vezes não se encontram preparados para o exercício da docência, daí a importância de um aperfeiçoamento social, histórico, político e principalmente didático que levará o professor a refletir sobre suas práticas pedagógicas enquanto formador.

Segundo Pimenta e Anastasiou (2008, p. 141), as oportunidades de emprego "vêm aumentando com a expansão das instituições particulares de ensino em todo o território nacional, tal expansão não está sendo acompanhada de um processo de profissionalização".

Com o aumento das Instituições de Ensino Superior e um aumento na oferta de cursos, tanto já existentes quanto novos, houve um aumento no número de vagas ofertadas, abrindo-se $o$ acesso às universidades às parcelas de pessoas que antes era de difícil acesso ao ensino superior. O resultado disso é uma diversidade cultural muito maior e a necessidade de que o docente saiba lidar com tamanha diversidade de culturas, além de se deparar com alunos não tão preparados tanto em saberes quanto emocionalmente para o ingresso na universidade.

Levando em consideração todos estes fatores há uma preocupação quanto a formação dos professores que atuaram no atual ensino superior, tanto inicial quanto a continuada e deveremos levar em consideração os questionamentos feitos por Morosini (2000, p.11): "Quem são (serão) estes novos professores? Estarão 
preparados didaticamente? ", pois afirma Morosini que há uma íntima relação entre o desempenho didático do professor e o desempenho do aluno.

Sendo assim a formação continuada deve ser tratada de forma séria e eficaz e as Instituições de Ensino Superior devem estar engajadas neste processo, oferecendo a seus docentes apoio e incentivo com propostas a curto, médio e longo prazo, as quais devem estar inseridas em seus Planos Político Pedagógicos.

Para Marques (2000, p.209):

Todas as instituições responsáveis pela educação devem ser envolvidas nos processos da formação continuada do educador. Cumpre, no entanto, dediquemos aqui atenção especial às responsabilidades específicas da universidade. Escola da educação do educador, à universidade não é apenas o processo formativo formal. Deve a ele dar continuidade e propiciar-Ihe as rupturas exigidas pelo exercício da profissão na concretude das exigências renovadas. Importa assume como atribuição sua os estágios da formação inicial como os da formação continuada dos educadores, mesmo porque não poderia cumprir com uma das tarefas sem a outra.

$\mathrm{Na}$ docência superior quase sempre é exigido do professor habilidades das quais nem sempre ele consegue adquirir na sua graduação, para sanar este problema faz-se necessário à formação continuada através de cursos de curta, média ou longa duração, nos quais ele será capaz de analisar e reciclar sua prática docente.

A formação continuada é um processo permanente e necessário para o professor universitário e pode ser dada por oficinas, cursos de curta duração, palestras, congressos além de Pós Graduação strictu e latu sensu, o strictu sensu confere títulos de mestre ou doutor, destina-se aqueles que desejam se aprofundar nas práticas de pesquisa duram de 2 a 4 anos e requerem uma dedicação maior e o lato sensu conhecido como especialização não concede títulos e sim um certificado tem duração de 18 meses e requer uma dedicação menor.

Independentemente do tipo de formação continuada a ser seguida ela não deve ser padronizada, pois deve respeitar e reconhecer as diferentes etapas da carreira do docente conforme apontado por Candau (1996, p.143): 
Todo processo de formação continuada de professores tem que ter com referência fundamental $o$ saber docente, o reconhecimento e a valorização do saber docente. Para um adequado desenvolvimento de formação continuada, é necessário ter presentes as diferentes etapas do desenvolvimento profissional do magistério $13 / 4$ não se pode tratar do mesmo modo o professor em fase inicial do exercício profissional, aquele que já conquistou uma ampla experiência pedagógica e aquele que já se encaminham para a aposentadoria.

O docente é um profissional que deve estar sempre em formação, o propósito maior da formação continuada do professor universitário é estimular a criticidade, a criatividade, a pesquisa, a reflexão principalmente de suas práticas pedagógicas e para que isso ocorra ela deve ser feita de forma diversificada em cursos de curta, média ou longa duração, dando-se maior ênfase aos cursos strictu sensu.

Segundo Cunha (2006), a formação do professor universitário,

[...] tem sido entendida por força da tradição e ratificada, como atinente quase que exclusivamente aos saberes do conteúdo de ensino. Esperase que o professor seja, cada vez mais, um especialista em sua área, tendo-se apropriado com o concurso da pós-graduação Stricto sensu, do conhecimento legitimado academicamente no seu campo científico. O domínio do conteúdo, por sua vez, deve ser alicerçado, nas atividades de pesquisa que garantam a capacidade potencial de produção científica (CUNHA 2006, p. 258).

Como já foi descrito anteriormente, o docente não é apenas um transmissor de conhecimentos, ele é um mediador, um facilitador e tem a responsabilidade de ajudar na construção dos saberes de seus alunos e transformá-los em profissionais críticos, reflexivos e preocupados em como irão aplicar em sua vida e na sociedade os conhecimentos adquiridos.

O docente deve ter uma prática pedagógica atualizada e incorporada em seu cotidiano e deve constantemente ser avaliado pelos alunos para que possa buscar seu aperfeiçoamento, por isso as avaliações são importantes também para o professor, pois além de poder avaliar como seus alunos estão construindo seus saberes poderá avaliar também como ele no papel de mediador está sendo útil para essa construção. Dessa forma a formação continuada leva o docente a um maior compromisso com a 
educação, a refletir e aperfeiçoar suas práticas docentes, sempre preocupados com a qualidade do ensino.

Segundo Pimenta e Anastasiou,

O papel do professor será, então, de desafiar, estimular, ajudar os alunos na construção de uma relação com o objeto de aprendizagem que, em algum nível, atenda a uma necessidade deles, auxiliando-os na tomada de consciência das necessidades apresentadas socialmente a uma formação universitária. (PIMENTA E ANASTASIOU, 2008, p.215)

O que significa ser um docente preparado para o ensino Superior? Como deve ser a formação do docente para atuar numa IES? Essas questões levam em consideração uma série de questionamentos quanto ao fato do docente possuir formação adequada e estar preparado para ministrar aulas no ensino superior. Levanta também a questão de quais são os saberes necessários para a prática docente, bem como que competências devem ter para boa prática de docência no ensino superior.

Nas IES, amparado pela LDB ํㅜ 9.394/96 e o decreto 2.207/97 (lei que regulamenta o sistema de ensino brasileiro), o professor universitário não necessariamente precisa ter obtido título de pós-graduação strictu senso (mestrado e/ou doutorado), exige que uma IES possua uma parcela dos professores seja detentora desses títulos.

Há certo consenso de que a docência no ensino superior não requer formação no campo do ensinar. Para ela seria suficiente o domínio de conhecimentos específicos, pois o que a identifica é a pesquisa e/ou o exercício da profissional no campo. (PIMENTA, 2008)

Como menciona Pimenta (2008), de fato isso ocorre nos dias atuais, alguns professores, também denominados professor especialista (aquele que é graduado, porém não detém título de mestre ou doutor), que normalmente possui experiência profissional, vem de mercado, viveram experiências em situações profissionais. Isso não quer dizer que o conhecimento adquirido por este seja desprezível, muito pelo contrário, situações reais servem de modelos a serem empregados dentro de sala de aula. Todavia, muitos desses professores estão ali para "fazer um por fora", uma renda 
extra, e nesse contexto, o que se coloca em xeque é a qualidade com a qual toda essa rica experiência é colocada em sala e de que forma ela agrega valor a formação e conhecimento do aluno.

$\mathrm{Na}$ maioria das instituições de ensino superior, incluindo as universidades, embora seus professores possuam experiência significativa e mesmo anos de estudos em suas áreas específicas, predomina o despreparo e até um desconhecimento científico do que seja o processo ensino de e de aprendizagem, pelo qual passam a ser responsáveis a partir do instante em que ingressam em sala de aula. (PIMENTA, 2008)

Pimenta (2008) ainda coloca que esses cursos onde ingressam esses professores, já vêm formatados, com ementa dos cursos prontas, onde o planejamento é individual, o que pode gerar falta de padrão no processo de ensino e de aprendizagem. Eles não são norteados quanto à metodologia empregada, o mesmo acontecendo no que tange ao processo de avaliação. Não há necessidade de feedback quanto ao resultado, isto é, se o objetivo foi alcançado. Com isso nota-se que docência no ensino superior ultrapassa as fronteiras de sala de aula, gerando uma dúvida: Qual a finalidade do ensino de graduação?

A partir da década de 90, observou-se um expressivo aumento no número de instituições de ensino superior bem como o número de cursos novos oferecidos pelo Brasil. Com esse crescimento a demanda por professores também cresceu, o mercado aqueceu e novas oportunidades surgiram. Para suprir essa demanda houve necessidade de contratação de professores. Muitas dessas universidades, surgiram em função de uma questão urbana - se o aluno não pode se deslocar até uma IES. A IES vai até ele. Hoje os grandes centros urbanos das grandes capitais, estão repletos de IES para diminuir tempos e movimentos dos alunos.

Essa crescente demanda por professor gerou uma queda na qualidade do ensino. Professores despreparados sob a ótica pedagógica e sem didática para educar, trazendo apenas seu conhecimento de mercado de trabalho. 
Países mais desenvolvidos já se mostram preocupados com a questão da qualidade do ensino, e já estão se mobilizando a fim de identificar os pontos a serem trabalhados. E dessa forma Pimenta declara da importância de estreitar a participação do professor na administração e gestão dos departamentos de ensino das IES. Sua atuação não deve ficar limitada ao cenário de sala de aula. Deve estar totalmente inserido no projeto pedagógico proposto, pois é parte integrante do todo, e acima de tudo ele é quem está na ponta com o discente.

Ao pesquisar pelo termo pedagogia em literaturas, revistas ou mesmo em sites pela internet encontraremos uma série de definições:

- A Pedagogia é a ciência ou disciplina cujo objetivo é a reflexão, ordenação, a sistematização e a crítica do processo educativo.

- Função ou trabalho do professor; Ensino; Arte ou ciência de ensinar; Métodos de instrução.

- Condução do saber. Preocupação com o ato de ensinar e de aprender.

Nota-se que nas definições de pedagogia, comumente estão presentes as palavras, saber, educação, ensino, ciência, instrução, teoria, prática, professor, docência, escola, dentre outras. Segundo Libâneo (1998), pedagogia tem a seguinte definição: Teoria que investiga a teoria e a prática da educação nos seus vínculos com a prática social global.

A partir das definições supra, observa-se que a pedagogia não está só e somente relacionada à educação, tem como elo a prática social, o que se justifica pelo fato de a educação ser um dos meios de socialização do indivíduo. Como ressalta Libâneo, a pedagogia está presente não estritamente no complexo educacional, mas em todos os setores da sociedade.

Um dos fenômenos mais significativos dos processos sociais contemporâneos é a ampliação do conceito de educação e a diversificação das atividades educativas, levando, por consequência, a uma diversificação da ação pedagógica na sociedade. 
Em várias esferas da prática social, mediante as modalidades de educação informais, não-formais e formais, amplia-se a produção e disseminação de saberes e modos de ação (conhecimentos, conceitos, habilidades, hábitos, procedimentos, crenças, atitudes), levando a práticas pedagógicas. Estamos diante de uma sociedade genuinamente pedagógica, conforme expressão de Beillerot. (LIBÂNEO, 2001)

Pode-se observar que a prática pedagógica possui leque de abrangência bem maior do que somente na educação. É dentro desse contexto que o docente deve atuar e explorar novas atividades e oportunidades para o desenvolvimento humano, trazendo para dentro de sala conhecimentos e saberes, diversificando a forma de relação com o indivíduo aluno e o grupo de sala de aula.

Para traçar um perfil de como era o ensino superior em seu início no Brasil ( $O$ ensino superior aportou em $1808 \mathrm{com}$ a chegada da família real portuguesa ao país), basta olharmos um pouco para o passado, onde o foco era a formação de profissionais para os exercícios de certas profissões e, portanto, a forma de ensino visava estritamente o conhecimento científico, onde o ensino era praticado por profissionais que detinham o conhecimento, mas sem nenhum suporte ao ensino e aprendizado, transformandoo num processo sem prazer.

O professor atuava meramente com um transmissor, ou multiplicador de conceito, o aluno não era o foco principal, mas sim a passagem de conhecimento. Os professores eram figuras de renome, com sucesso profissional. A filosofia era: quem sabe ensina, e muito bem aceito pela sociedade e para a cultura da época.

O docente nos dias de hoje enfrenta um problema com relação ao educar. Que competências deve colocar em prática nas atividades do seu dia-a-dia profissional? É deveras importante definir efetivamente a função do professor, priorizando o aprendizado do aluno, haja vista esse ser um dos principais objetivos do ensino superior.

Conforme mostrado por Behrens (2003) o papel do professor transcende a somente passar o conhecimento. $O$ professor, na abordagem holística, tem um papel 
fundamental na superação do paradigma da fragmentação. Buscando ultrapassar a reprodução para a produção do conhecimento, o professor precisa buscar caminhos alternativos que alicercem ações docentes relevantes, significativas e competentes. O modelo educacional que se faz presente no Brasil e que não conduz a uma efetiva aprendizagem é o da transmissão de conhecimento formando meros repetidores de conteúdo, conceito usado por (MORIN,2016)

Agora se apresenta possíveis caminho nesse contexto que se faz necessário para pensar concomitantemente em interdisciplinaridade e transdisciplinaridade. Promover uma revisão do currículo de formação profissional no ensino superior, promovendo maior integração entre as disciplinas e os saberes ali contidos, escapando assim do modelo pedagógico baseado em matérias isoladas umas das outras, sem conectividade, como se fora um quebra-cabeças insolúvel, Mudanças no ensino superior seriam necessárias. O ensino superior certamente irá rever seus currículos de formação profissional à luz das novas exigências que estão postas para o exercício competente das profissões em nossa sociedade e, assim, formará sujeitos capazes de refletir e fazer refletir (BEHRENS,2017)

Porém o problema não se resume só e somente a formação do docente, é importante levar em consideração seus saberes, as competências necessárias ao exercício da docência, a formação voltada para a pesquisa com foco na construção do conhecimento e na construção empírica do conhecimento. Situar o saber do professor na interface entre o individual e o social, entre o ator e o sistema, a fim de captar a sua natureza social e individual como um todo (TARDIF, 2000)

A formação docente vem sendo questionada no Brasil bem como outros países sulamericanos e europeus, muito impulsionadas pelas mudanças na sociedade, como econômicas, tecnologia da informação e comunicação, políticas e na própria educação, como por exemplo, a desvalorização da profissão de professor. Nesta seara, surge a figura do professor reflexivo. A prática reflexiva possibilita ao professores auto avaliar-se, refletir suas práticas, didática, conceitos, conhecimentos e de forma geral sua pedagogia. 
A prática reflexiva no docente tem sido vista com bons olhos por vários educadores e pesquisadores em educação. Segundo Zeichner (1993), alguns pontos foram relevantes para a construção da prática reflexiva:

- O professor deixa de ser apenas aquele que passa o conhecimento e passa a ser responsável por definir sua forma de trabalho.

- Passa a utilizar seus saberes, os saberes tácitos desvinculando-se apenas dos saberes acadêmicos, ou seja, é mais participativo e sua visão tem relevância no processo de ensino e aprendizado.

- A prática docente passa a ser reconhecida com processo de melhoria contínua.

Nos dias de hoje, com o mudo globalizado, informatizado, informação chegando por qualquer meio que se possa comunicar, a sociedade é, por assim dizer, "bombardeada" de informação. Todavia a informação por si só pode derivar uma grande vertente de conhecimentos. Esse é um dos pontos que o professor deve refletir. Avaliando que tipo de informação está lidando, seu nível de agregação, questioná-la, deve colocar em discussão com o aluno, trocar esse conhecimento, e dentro dessa troca enriquecer o conhecimento.

Antônio Nóvoa, em entrevista concedida por à TV Educativa do Brasil (TVE) em 2001, aponta que o professor sempre foi reflexivo e que o paradigma do professor reflexivo, isto é, do professor que reflete sobre a sua prática, que pensa, que elabora em cima dessa prática é o paradigma hoje em dia dominante na área de formação de professores. Por vezes é um paradigma um bocadinho retórico e eu, um pouco também, em jeito de brincadeira, mais de uma vez já disse que o que me importa mais é saber como é que os professores refletiam antes que os universitários tivessem decidido que eles deveriam ser professores reflexivos. Identificar essas práticas de reflexão - que sempre existiram na profissão docente, é impossível alguém imaginar uma profissão docente em que essas práticas reflexivas não existissem - tentar identificá-las e construir as condições para que elas possam se desenvolver. 
Ainda em sua entrevista, Antônio Nóvoa, afirma que dado fatores, como sociedade mais complexa no seu modo de ser e a tecnologia da informação, o professor de hoje precisar estar ciente que necessita lidar com mais saberes do que existia no passado. Indaga ainda que o professor não se resumir a detenção do conhecimento, se faz necessário saber transmitir o conhecimento, e para tal colocou com essencial praticar as competências para ensinar. Competências essas declaradas por Philippe Perrenoud (2000) em 10 Novas Competências para Ensinar.

Nota-se, portanto, que as transformações sociais impulsionaram o professor à prática de reflexão sobre si e sobre outros sistemas que estão ao seu redor. O modelo "engessado" do passado acadêmico não tem mais espaço nos dias de hoje. O modelo de educação necessitou adaptar-se a uma vida social cada vez mais crítica, questionadora e exigente. A prática docente não pode ser um canal de uma só via precisa ser via de mão dupla - troca e de fato continuada.

No universo acadêmico atual, observa-se várias transformações. Tais transformações implicam em uma nova forma de entender o conhecimento, e dessa forma o conhecimento é construído pelo binômio professor-aluno. Nessa nova forma de construção do conhecimento, sociedade e educação passam a ser um fornecedor do outro, e assim sendo, a educação não consegue mais se dissociar da sociedade da informação, na qual a tecnologia da informação e comunicação acaba por exercer fortes influências no processo de ensino e aprendizagem

O avanço tecnológico ocorrido no mundo pós-guerra até os dias de hoje, e em especial o avanço da informática, afetam o modo de pensar, de agir, de trabalhar e a educação não está fora desses impactos. A TIC (tecnologia da informação e comunicação) está presente em grande parte das escolas e universidades do mundo todo. Professores utilizam hoje recursos tecnológicos como TV, Data show, Computador, Smart Board, dentre inúmeros outros recursos, que dão suporte, agilidade e qualidade a sua aula.

A disciplina agora é ministrada não de maneira estática, como era nos tempos do quadro-negro e giz. Ela tem movimento, som, imagem, como se tivesse vida. 
O professor pode ser chamado hoje de "Professor 24 Horas". Muitos recursos de se comunicar estão à disposição dos alunos e dos professores, seja por e-mail, programas de mensagens como WhatsApp, Google Hangouts. Também existem as comunidades virtuais, como Facebook, Twitter e sites mantidos por professores onde disponibilizam material de apoio além de permitir que dúvidas sejam registradas no site para posterior resposta.

E quando se pensa em todo esse aparato de ferramentas, percebe-se que a informação trafega a velocidades "astronômicas". O professor nesse ínterim, deve ficar muito atento pois o aluno de hoje já chega em sala informado. E é aí que pode estar o grande trunfo, pois o professor tem nessa rede de comunicação, conhecimento e informação a oportunidade de transcender o conteúdo, trazendo para o cotidiano da educação situações reais, promovendo ainda mais um trabalho de inter e transdiciplinaridade.

\section{CONCLUSÃO}

É notório que o docente se vê numa situação de responsabilidade exacerbada, pois ele tem a função de perpetuar o saber, integrar, socializar, passar o conhecimento, formar cidadão, avaliar, motivar, trocar, aprender, estar disponível intra e extraclasse, dentre numerosas outras tarefas. Tem de estar formado e informado, o mais atualizado possível bem como ter antevisão, tudo isso com salários pouco motivantes e investimentos profissionais bem abaixo do necessário, sem contar ainda com uma série de competências pertinentes a um docente.

É cobrado, e porque não dizer quase "culpado" por problemas e pela qualidade de ensino, apesar de no ensino superior passar pouco tempo com seus alunos, isso se comparado aos ensinos fundamental e médio, onde o contato é maior. Vale; analogamente; aquela máxima de que se um gerente for ruim no seu dia-a-dia dentro de um banco, o cliente indaga que o banco não presta.

Apesar de tudo é possível que docentes sejam preparados e lapidados com todas essas características. Um país que almeja crescimento, que deseja ver seus futuros 
formandos criando divisas para o país e formando uma sociedade justa, coesa e perene, tem de investir em educação, municiar e preparar seu corpo docente de maneira adequada para que supra suas necessidades e atinja suas metas futuras. Professores mal preparados significam resultados abaixo do esperado, e acarreta geração de custos desnecessários, revisão de regras e normas, ao passo que investir parcimoniosamente e planejadamente pode significar resultados positivos. A educação não pode ter soluções imediatistas e radicais, é gradativo, pode levar dez, vinte ou cinquenta anos. Só por citar, países como Alemanha e Japão, aniquilados no mundo pós segunda guerra mundial, se reergueram em grande parte devido ao investimento em educação, e isso implica dizer docente de qualidade e recursos para o trabalho.

De volta as questões iniciais desse estudo comparativamente aos resultados teóricos obtidos percebem se que uso de novas tecnologias de fato tem promovido mudanças no cenário educacional. Se por um lado observamos vantagens como a proximidade do professor ao aluno e a maior eficiência no processamento de informações para gestão, por outro lado, ainda nos deparamos com a dificuldade de acesso as novas tecnologias por todos os atores envolvidos nesse processo de mudança.

Dessa forma, percebe se que o cenário educacional tem buscado cada vez mais novas formas de gestão e modelos pedagógicos pautados na tecnologia, atingindo assim um maior número de professores e alunos. A sala de aula não perdeu sua importância apenas se tornou mais moderna, possibilitando o acesso à; informação bem mais rápida na busca de conhecimento. As mudanças tecnológicas aprimoraram boa parte da gestão educacional, o gerenciamento da informação dentro das instituições tornou se ágil e mais segura.

Esta necessidade de estarem "conectadas" às mudanças e o uso contínuo da tecnologia aproximaram os discentes dos docentes e quebrou vários paradigmas, possibilitando o acesso das mais diversas pessoas que antes não tinham nenhuma condição ou tempo de se relacionar em uma sala de aula ou ambiente virtual de aprendizagem. 
A tecnologia, bem como outros meios formativos devem estar, no caso desse artigo, voltados à formação de um sujeito que especialista, mestre ou doutor esteja pronto para propor novas intervenções pedagógicas fomentando o saber concreto no espaço universitário. por meio da interdisciplinaridade ou de outras estratégias que levem o aprendiz a refletir sobre o proposto enquanto conteúdo, porém muito mais, saiba, de modo reflexivo, olhar o seu entorno e provocar transformações que the valha e valha para os demais entes sociais

A partir deste estudo pode se perceber a necessidade do desenvolvimento de novos estudos direcionados a formação do professor universitário que necessita ser reflexivo para tornar seus formandos também detentores de um saber reflexivo.

\section{REFERÊNCIAS}

BEHRENS, M. A. Paradigmas da Complexidade: Metodologia de Projetos, Contratos Didáticos e Portfólios. Rio de Janeiro: Editora Vozes,2017.

BEHRENS, Marilda Aparecida (Org.); SANT'ANA, Edith Lopes (Org.); JOSÉ, Eliane Mara Age (Org.); VIDAL, Eva Sueli Nasser (Org.); NICKEL, Fausta Araújo (Org.); BATISTA, leda Pinheiro Lima (Org.); MONTOYA, Irmgard Krüger (Org.); MOCHON, Lili Pachulski (Org.); SALAZAR, Norma Isabel Werner (Org.); MIRANDA, Simone de (Org.); PACHECO, Yara Nazarena Pinheiro Lima Baptista de M (Org.). Docência Universitária na sociedade do conhecimento. 1. ed. Curitiba, PR: Champgnat, 2003.

CANDAU, Vera Maria Ferrão. Formação Continuada de professores: tendências atuais. In: REALI, Aline Maria de Medeiros Rodrigues e MIZUKAMI, Maria da Graça Nicoletti (orgs.). Formação de professores: tendências atuais. São Carlos: EDUFSCar, 1996.

CUNHA, Maria Izabel. Docência na universidade, cultura e avaliação institucional: saberes silenciados em questão. Revista Brasileira de Educação, Rio de Janeiro Brasil. 2006

FREIRE, Paulo. Pedagogia do oprimido. 36. Ed. Rio de Janeiro: Paz e Terra. 2003. 
JESUS, S. N. O stress dos professores e a indisciplina dos alunos: medidas para prevenção e resolução. In: AFONSO, A.; AMADO, J. S.; JESUS, S. N. Sentido da escolaridade, indisciplina e stress nos professores. Porto: Asa, 1999. p. 39-48.

LIBANEO, José Carlos. Adeus Professor Adeus Professora? Novas exigências educacionais e profissão docente. São Paulo. 5. Ed. Cortez. 2001.

LIBANEO, José Carlos. Didática. São Paulo. Ed. Cortez. 1998

MARQUES, Mário Osório. Formação do profissional da educação. ljuí: Unijuí, 2000.

MASETTO, Marcos. Docência Na Universidade. São Paulo, Papirus. 1998.

MORIN, Edgar.O Problema Epistemológico da Complexidade. Portugal: EuropaAmérica. Publicações Europa-América,2016.

MOROSINI, Marília Costa. Docência universitária e os desafios da realidade nacional. In: MOROSINI, Marília et al. (orgs.) Professor do Ensino Superior: identidade, docência e formação. Brasília: INEP, 2000

NÓVOA, A. Formação de professores e profissão docente. In.: NÓVOA, A. Os Professores e sua Formação. 3. ed. Lisboa: Dom Quixote, 1997. p. 15-33.

PAIVA, E. V. de. A formação do professor crítico-reflexivo. In.: PAIVA, E. V. (org.). Pesquisando a formação de professores. Rio de Janeiro: DP\&A, 2003.

PIMENTA, S. G.; ANASTASIOU, L. das G. C. Docência no Ensino Superior, 3.ed. São Paulo: Cortez Editora, 2008

PIMENTA, Selma Garrido; LIMA, Maria Socorro Lucena. Estágio e docência. 3. Ed. São Paulo: Cortez, 2008. (Coleção docência em formação. Série saberes pedagógicos). 
SANTOS, B. Gestão da sala de aula para prevenção da indisciplina: a importância da formação inicial. In: ESTRELA, A.; FERREIRA, J. (Orgs.). Indisciplina e violência na escola. XI Colóquio na AFIRSE, 2002. p. 159-165.

SCHÖN, D. La formacion de profesionales reflexivos. Barcelona: Paidós, 1992.

TARDIF, Maurice. Saberes profissionais dos professores. Revista Brasileira de Educação e conhecimentos universitários, n.13, p. 5-24, Jan/abr., 2000.

Enviado: Julho, 2019.

Aprovado: Setembro, 2019. 